\title{
Can Private Provision of Primary Care Contribute to the Spread of Antibiotic Resistance? A Study of Antibiotic Prescription in Sweden
}

\author{
David Granlund ${ }^{1} \cdot$ Yana V. Zykova²
}

Accepted: 1 October 2020 / Published online: 23 October 2020

(c) The Author(s) 2020

\begin{abstract}
Background Growing rates of antibiotic resistance, caused by increasing antibiotic use, pose a threat by making antibiotics less effective in treating infections.

Objective We aimed to study whether physicians working at privately and publicly owned health centres differed in the likelihood of prescribing antibiotics and choosing broad-spectrum over narrow-spectrum antibiotics.

Methods To estimate the effect of ownership on the probability of a prescribed drug being an antibiotic, we analysed all 4.5 million prescriptions issued from 2011 to 2015 at primary health centres in Västerbotten, Sweden. We controlled for patient age, sex, number of prescriptions per patient, and month of prescription, and used a maximum likelihood logit estimator. We then analysed how ownership affected the likelihood of a prescribed antibiotic being broad spectrum. We also used aggregated data to estimate the impact of the number of private health centres on the number of antibiotic prescriptions per inhabitant and the proportion of broad-spectrum antibiotics.

Results Holding other factors constant, private physicians were $6 \%$ more likely to prescribe antibiotics and 9\% more likely to choose broad-spectrum antibiotics. An increase by one additional private health centre was positively associated with an increase in the number of antibiotic prescriptions per inhabitant and a higher proportion, although not significant, of broadspectrum antibiotic prescriptions.

Conclusion Our findings suggest that private physicians prescribe more antibiotics, especially broad-spectrum antibiotics, than public physicians. Therefore, it is crucial to provide health centres with incentives to follow guidelines for antibiotic prescription, especially when the level of private provision of primary healthcare is high.
\end{abstract}

David Granlund and Yana V. Zykova contributed equally and share first authorship.

Electronic supplementary material The online version of this article (https://doi.org/10.1007/s41669-020-00234-7) contains supplementary material, which is available to authorized users.

Yana V. Zykova

yana.zykova@uit.no

1 Department of Economics, Umeå University, Umeå, Sweden

2 School of Business and Economics, The Arctic University of Norway (UiT), Troms $\varnothing$, Norway

\section{Key Points for Decision-Makers}

We found that physicians working at privately owned health centres were $6 \%$ more likely to prescribe antibiotics than physicians at publicly owned health centres. In addition, the former were $9 \%$ more likely to choose a broad-spectrum antibiotic when prescribing any antibiotic. These results were obtained by controlling for other factors such as patient characteristics.

It may be especially important to monitor antibiotic prescription at private health centres and to give them economic incentives to adhere to guidelines for antibiotic prescription. 


\section{Introduction}

Antibiotics introduced into a specific environment exert selective pressure on the bacterial populations inhabiting that environment. This gives an advantage to antibioticresistant bacteria which survive, reproduce, and can spread further. Antibiotic resistance (AR) is growing rapidly due to the intensive use of antibiotics, making these drugs increasingly less effective in treating infectious diseases. AR poses a significant threat to current and future generations [1].

The problem of inappropriate antibiotic prescription is especially relevant in primary care because the majority of antibiotic prescriptions are for respiratory tract infections (RTIs), which are frequent diagnoses in primary care; however, the cause of most RTIs is viruses, for which antibiotics are ineffective. Fleming-Dutra et al. [2] found that almost half of the antibiotic prescriptions for RTIs in the US were evaluated as inappropriate. There are many possible reasons why antibiotics are prescribed even when they are ineffective. For example, patients' impatience and limited knowledge may increase their readiness to receive antibiotic treatment. They may consider the doctor's willingness to prescribe antibiotics as a characteristic of quality and care $[3,4]$. This is especially relevant for countries with restricted over-the-counter sales of these pharmaceuticals. If uninformed patients demand antibiotics for non-bacterial infections, and if the profitability of a healthcare centre depends on the number of patient visits, competition between these centres may create incentives to overprescribe antibiotics [5-7].

Previous research has shown that such economic incentives may play an important role in physicians' medical decision making [8]. However, there are not many studies on the effect of economic incentives on prescription of antibiotics. Notable exceptions are Hutchinson and Foley [9], Fogelberg [10], and Ellegård et al. [11]. Hutchinson and Foley found that physicians working under fee-for-service in Newfoundland, Canada, prescribed significantly more antibiotics than salaried physicians. Using aggregated Swedish data, Fogelberg found that stronger competition between healthcare providers significantly increased the number of antibiotic prescriptions as long as the provider was not required to pay for the prescribed drugs. Using yearly data on the consumption of pharmaceuticals by Swedish children, Ellegård et al. found that reimbursement schemes based on antibiotics-related pay-for-performance indicators stimulated more appropriate antibiotic prescription.

In this paper, we focus on the effect of type of ownership of healthcare centres on the prescription of antibiotics. Silverman et al. [12] and Devereaux et al. [13] found a significant positive correlation between the proportion of profit-driven hospitals and health expenditure, while Kessler and McClellan [14] found that private hospitals with profit incentives had significantly lower costs than non-profit hospitals for treating heart attack, controlling for treatment quality. The latter indicates that private provision of health care can increase efficiency. Granlund [15] found that private doctors were more likely to disallow generic substitution. More recently, Ellegård [16] studied how pay-for-performance incentives affected primary care providers' compliance with hypertension drug guidelines and found that private providers reacted more strongly to the economic incentives. To our knowledge, there are no studies to date addressing the impact of ownership of healthcare centres on the prescription of antibiotics.

The ability of private health centres to pay salaries and generate profits directly depend on the number of patients visits and patients listed at the health centre. We therefore hypothesised that private health centres have stronger incentives to please patients, and one way to do this can be to prescribe antibiotics to patients who ask for this.

The main aim of our study was to determine whether there is a significant difference between private and public primary healthcare centres in antibiotic prescription. To answer this question, we analysed prescriptions written at public and private primary healthcare centres in Västerbotten, Sweden, primarily in two ways. First, we investigated whether the probability of the prescribed drug being an antibiotic varies systematically across ownership type. Second, we tested whether there are systematic differences in the prescription of broad- versus narrow-spectrum antibiotics between private and public centres. The motivation for our second approach is that the rapid growth of AR has forced physicians to turn to more frequent prescription of broad-spectrum antibiotics. These antibiotics target a wider range of bacterial species, and hence contribute even more to the development of AR [17]. Thus, it is critical that inappropriate use of broad-spectrum antibiotics is reduced. However, patients may perceive prescription of a broad-spectrum antibiotic as a signal of high-quality healthcare because the probability of a patient being cured after the first prescription is higher in this case. Doctors' willingness to please patients based on economic incentives, together with other possible factors (e.g. diagnostic uncertainty), may motivate them to prescribe broad-spectrum antibiotics more frequently. We also analysed the impact of a new private health centre on the number of antibiotic prescriptions per capita and the share of broad-spectrum antibiotics.

\section{Institutional Background and Incentives}

Sweden is divided into 21 counties that are responsible for primary healthcare. Although most of the health centres are managed by the county councils, the operation of 
about $40 \%$ is outsourced to private providers contracted and financed by the counties [18]. Health centres are usually organised as team-based practices with general practitioners (GPs), nurses, midwives, gynaecologists, psychologists, social workers, behavioural therapists, and physiotherapists [19]. On average, there are four GPs in each health centre [18].

In 2010, Sweden implemented the System of Choice reform, aimed at increasing competition in primary healthcare by making entry to the market free for primary care providers fulfilling minimum requirements set by the county councils [20]. The System of Choice reform attracted new private providers to the market, and gave patients the free choice of registering with either a private or public provider. Patients register with a health centre rather than with a specific GP. Registration is obligatory for all residents except those from Stockholm County. If a patient does not make an active choice of provider, then he/she is listed in a public or private health centre suggested by the county council. The most common suggestion is the centre closest to the patient's residence. Although everyone in Sweden is free to choose a primary healthcare provider, only $30 \%$ choose a health centre different from the one suggested by the county [21].

Health centres should accept all new applicants and can pose only temporary restrictions on the number of patients. Patients registered at one centre can still visit GPs at other health centres [18]. Both public and private centres receive a mixture of capitation payment for registered patients (about 80\%), fee-for-service (17-18\%) and performance-based compensation (2-3\%) for achieving different targets for quality [18]. In Västerbotten, capitation payments for registered patients constituted $87 \%$ of reimbursement to health centres.

Västerbotten County, located in the north of Sweden, is the second largest county, in terms of area, in the country, and consists of 15 municipalities. There are about 260,000 inhabitants in the county, $45 \%$ of whom live in the municipality of Umeå. At the beginning of our study period from 2011 to 2015, there were 6 private and 32 public health centres in Västerbotten, but in March 2014 a new private health centre opened in the municipality of Umeå. The proportion of private health centres in Västerbotten is much lower than that at the national level, which may partly be because the requirements that primary care providers have to fulfil to enter the market are higher in this county than in most other counties. For example, each health centre must offer its patients maternity care, children's care, and rehabilitation services $[22,23]$. The high requirements also reduce the heterogeneity across health centres by restricting entry for health centres with limited services. Moreover, the listing system in Västerbotten has been criticised because, after the System of Choice reform was introduced in 2010, patients who did not make an active choice of provider stayed on the list of their previous health centre [24]. This principle created difficulties for new private providers because they had to start their practice with no patients on the list, and their ability to pay salaries and generate profits directly depend on capitation and payments for patient visits. Therefore, we hypothesised that private health centres have more incentives to attract new patients by pleasing them.

\section{Methods}

\subsection{Data}

To test our hypotheses, we used a dataset containing all fillings of prescriptions written at health centres in Västerbotten County from January 2011 through December 2015 and dispensed by Swedish pharmacies until April 2016. The dataset consists of approximately 11 million observations and includes a large number of variables, such as the patient's age at the time of drug prescription, sex, and area of residence. The information about each prescription includes the date of prescription and the workplace of the prescriber.

After excluding prescriptions written by health professionals other than physicians (e.g. nurses) and those with missing information, e.g. the Anatomical Therapeutic Classification (ATC) code, about 10 million observations remained. A large proportion of drugs was prescribed with an option for repeat purchases. As we were interested in analysing physicians' prescription decisions, we removed all repeat fillings and arrived at a dataset of 4,596,194 observations.

\subsection{Empirical Models}

\subsubsection{Model 1 for the Effect of Ownership on Antibiotic Prescription}

In the analysis of whether the type of health centre ownership affected the frequency of antibiotic prescription, we included all prescriptions (antibiotic and non-antibiotic) and estimated the effect of ownership on the probability of a prescribed drug being an antibiotic. The dummy variable Antibiotic was defined to equal one when the drug belonged to the 'J01-Antibacterial drugs' group according to the ATC classification, with methenamine (J01XX05) excluded. Methenamine is not considered an antibiotic but is rather an antiseptic substance that has no influence on AR [25]. Based on workplace information, we created the dummy variable Private, which indicates whether the primary centre was private or public. Health centres may significantly differ in the age and sex of patients, therefore we included in the analysis a dummy variable taking the value of 1 if the patient was a 
Table 1 Classification of broadand narrow-spectrum antibiotics

\begin{tabular}{ll}
\hline Narrow-spectrum antibiotics & Broad-spectrum antibiotics \\
\hline PcV (phenoxymethylpenicillin) [J01CE02] & Amoxicillin [J01CA04] \\
Nitrofurantoin [J01XE01] & Amoxicillin and enzyme inhibitor [J01CR02] \\
Pivmecillinam [J01CA08] & Doxycycline [J01AA02] \\
Trimethoprim [J01EA01] & Cephalosporins [J01DB + J01DC + J01DD + J01DE] \\
& Erythromycin [J01FA01] \\
& Quinolones [J01MA02 + J01MA06]
\end{tabular}

The codes in square brackets are Anatomical Therapeutic Chemical classification codes assigned by the World Health Organization women, as well as dummy variables for patients' age groups. We grouped patients into nine age groups: 0-2, 3-6, 7-12, $13-18,19-25,26-45,46-65,66-85$ and $\geq 86$ years of age. Controlling for the patient's age is important because, for example, the prescription of non-antibiotic drugs to children is substantially lower than for adults.

We defined the variable Prescriptions_per_patient for each health centre each year as the total number of prescriptions divided by the number of registered patients. We used this variable to control for the fact that some health centres may systematically prescribe more drugs per patient (antibiotic and non-antibiotic), for example due to treating patients with more severe diseases. If private and county-employed physicians prescribe the same number of antibiotics per patient, but private physicians prescribe fewer non-antibiotics, then the variable Prescriptions_per_patient prevents the estimate for Private from becoming positive just because a higher share of prescriptions written by private physicians are for antibiotics. We also controlled for the municipality where the health centre was located (Muni_centre), municipality-specific linear trends (Muni_centreTrend) and dummies for 59 of the 60 months studied (YearMonth). The equation for model 1 is (Eq. 1):

$$
\begin{aligned}
\operatorname{Pr}\left(\text { Antibiotic }_{i}=1\right)= & F\left(\alpha+\beta_{1} \text { Private }_{i}+\beta_{2} \text { Women }_{i}+\sum_{a=2}^{9} \gamma_{a} \text { Age group }_{a i}\right. \\
& +\beta_{3} \text { Prescription_per_patient }_{i}+\sum_{m=2}^{15} \delta_{m} \text { Muni_centre }_{m i} \\
& \left.+\sum_{m=2}^{15} \eta_{m} \text { Muni_centreTrend }_{m i}+\sum_{y=2}^{60} \theta_{y} \text { YearMonth }_{y i}+\varepsilon_{i}\right) .
\end{aligned}
$$

\subsubsection{Model 2 for Differences in the Prescription of Broad- and Narrow-Spectrum Antibiotics}

With the second model, we examined whether there was a systematic difference in the prescription of broad- versus narrow-spectrum antibiotics between private and public health centres. Broad is a dummy variable with a value of 1 for the medications listed as broad-spectrum antibiotics in Table 1. Our selection of specific types of antibiotics was derived from Fogelberg [10] and recommended by medical experts at the Swedish Institute for Communicable Disease Control. Some antibiotic prescriptions (about 20\%) from the original dataset belong to neither the narrow-spectrum nor broad-spectrum group (in the way we defined them).

We extracted all prescriptions for antibiotics that were classified as either broad- or narrow-spectrum antibiotics according to Table 1, which gave us 152,055 observations that we applied to the equation for model 2 (Eq. 2):

$$
\begin{aligned}
& \operatorname{Pr}\left(\text { Broad }_{i}=1\right)= F\left(\alpha+\beta_{1} \text { Private }_{i}+\beta_{2} \text { Women }_{i}+\sum_{a=2}^{9} \gamma_{a} \text { Age group }_{a i}\right. \\
&+\sum_{m=2}^{15} \delta_{m} \text { Muni_centre }_{m i}+\sum_{m=2}^{15} \eta_{m} \text { Muni_centreTrend } \\
& m i \\
&\left.+\sum_{y=2}^{60} \theta_{y} \text { YearMonth }_{y i}+\varepsilon_{i}\right) .
\end{aligned}
$$

A maximum likelihood logit estimator was used to estimate models 1 and 2 . To examine the robustness of the results, several other estimations were performed. These are presented and discussed in the online Appendix.

Table 2 presents descriptive statistics for the variables in models 1 and 2 . It shows that the proportion of prescriptions for antibiotics, in particular broad-spectrum antibiotics, is higher for physicians working at private health centres. The descriptive statistics also show that $63 \%$ of antibiotics were prescribed to women.

\subsubsection{Models 3 and 4 for the Impacts of a New Private Health Centre}

Models 3 and 4 were used to assess whether the number of antibiotic prescriptions per inhabitant and the proportion of broad-spectrum antibiotics prescribed were affected by the number of private health centres in the patient's municipality of residence, N_Private. We consider this variable to be a proxy for the supply of private health centre services. As the variation in N_Private was limited to the opening of one new health centre, the estimates for this variable should be viewed as results from one case study. We lacked data for N_Private for the $1 \%$ of the prescriptions that were for 
Table 2 Descriptive statistics for models 1 and 2

\begin{tabular}{|c|c|c|c|c|c|c|}
\hline \multirow[t]{2}{*}{ Variable } & \multicolumn{3}{|l|}{ Model 1} & \multicolumn{3}{|l|}{ Model 2} \\
\hline & Sample & Antibiotic & Non-antibiotic & Sample & Broad-spectrum & Narrow-spectrum \\
\hline Private & 16.17 & 16.68 & 16.14 & 16.90 & 18.14 & 16.30 \\
\hline Women & 57.99 & 63.39 & 57.76 & 66.41 & 51.21 & 73.84 \\
\hline Prescriptions_per_patient & $3.77 \pm 1.00$ & $3.70 \pm 0.99$ & $3.77 \pm 1.00$ & & & \\
\hline Age group 0-2 & 0.66 & 3.52 & 0.53 & 3.96 & 2.97 & 4.45 \\
\hline Age group 3-6 & 0.69 & 4.35 & 0.53 & 4.80 & 2.95 & 5.70 \\
\hline Age group 7-12 & 0.73 & 3.67 & 0.60 & 3.83 & 2.18 & 4.64 \\
\hline Age group 13-18 & 1.12 & 5.41 & 0.94 & 4.61 & 3.37 & 5.22 \\
\hline Age group 19-25 & 2.66 & 8.60 & 2.40 & 7.93 & 6.57 & 8.59 \\
\hline Age group 26-45 & 11.51 & 18.37 & 11.22 & 17.88 & 17.74 & 17.95 \\
\hline Age group 46-65 & 30.39 & 22.71 & 30.72 & 22.47 & 27.97 & 19.78 \\
\hline Age group 66-85 & 42.72 & 26.79 & 43.40 & 27.78 & 29.92 & 26.72 \\
\hline Age group $\geq 86$ & 9.53 & 6.58 & 9.65 & 6.74 & 6.33 & 6.93 \\
\hline \multicolumn{7}{|c|}{ Municipality of the health centre } \\
\hline Nordmaling & 2.89 & 2.28 & 2.91 & 2.44 & 1.91 & 2.70 \\
\hline Bjurholm & 1.08 & 0.91 & 1.09 & 0.89 & 0.90 & 0.89 \\
\hline Vindeln & 2.49 & 2.33 & 2.49 & 2.36 & 2.40 & 2.34 \\
\hline Robertsfors & 2.96 & 2.48 & 2.98 & 2.48 & 2.80 & 2.33 \\
\hline Norsjö & 2.10 & 2.17 & 2.09 & 2.27 & 2.27 & 2.27 \\
\hline Malå & 1.96 & 1.97 & 1.96 & 1.98 & 1.99 & 1.98 \\
\hline Storuman & 3.29 & 3.19 & 3.30 & 3.11 & 3.19 & 3.08 \\
\hline Sorsele & 1.49 & 1.83 & 1.47 & 1.87 & 2.21 & 1.70 \\
\hline Dorotea & 1.55 & 1.28 & 1.56 & 1.21 & 1.30 & 1.16 \\
\hline Vännäs & 3.03 & 2.75 & 3.04 & 2.69 & 2.32 & 2.87 \\
\hline Vilhelmina & 3.62 & 3.89 & 3.61 & 3.77 & 4.53 & 3.40 \\
\hline Åsele & 1.70 & 1.56 & 1.71 & 1.56 & 1.66 & 1.51 \\
\hline Umeå & 40.10 & 41.35 & 40.05 & 41.52 & 41.50 & 41.53 \\
\hline Lycksele & 5.98 & 5.97 & 5.98 & 6.05 & 6.12 & 6.02 \\
\hline Skellefteå & 25.77 & 26.05 & 25.76 & 25.81 & 24.91 & 26.24 \\
\hline Observations & $4,596,194$ & 189,579 & $4,406,615$ & 152,055 & 49,940 & 102,115 \\
\hline
\end{tabular}

Percentages are reported for discrete variables, and means and standard deviations are reported for continuous variables. Descriptive statistics for the municipality-specific time trends and the 60 -month dummies are available upon request.

patients not living in Västerbotten, and therefore excluded these prescriptions when estimating models 3 and 4 . The equation for model 3 is (Eq. 3).

$$
\begin{aligned}
& \text { lnN_antibiotics }_{r y a s}= \beta_{1} \mathrm{~N} \_ \text {Private }_{r y}+\beta_{2} \text { Women }_{s}+\sum_{a=2}^{9} \gamma_{a} \text { Age group }_{a} \\
&+\sum_{r=2}^{15} \delta_{r} \text { Muni_patient }_{r}+\sum_{r=2}^{15} \delta_{r} \text { Muni_patientTrend } \\
& r y \\
&+\sum_{y=2}^{60} \eta_{y} \text { YearMonth }_{y}+\varepsilon_{r y a s} .
\end{aligned}
$$

The dependent variable is the natural logarithm of the number of prescribed antibiotics per resident in municipality $r$ in year-month $y$ of age group $a$ and sex $s$. Natural logarithms were used to allow N_Private to have the same percentage effect on the number of antibiotics prescribed in demographic groups with few antibiotic prescriptions per capita as in demographic groups with many antibiotic prescriptions per capita. For each municipality of residence and each year, we chose to have separate observations for each age group $\times$ sex combination to be able to control for differences in demographic composition across municipalities and time. We also controlled for municipality of residence of the patient (Muni_patient) and municipality-specific linear trends to avoid the coefficient for N_Private to be affected by differences in health between residents of Umeå (where the new health centre was opened) and residents of other municipalities. Muni_patient was identical to Muni_centre for $95 \%$ of the prescriptions, but we chose the former because it is less risk that patients' choices of place of residence are affected by preferences for antibiotics compared 
Table 3 Descriptive statistics for models 3 and 4

\begin{tabular}{lll}
\hline Variable & Model 3 & Model 4 \\
\hline N_antibiotics & $0.012 \pm 0.008$ & \\
lnN_antibiotics & $-4.595 \pm 0.581$ & \\
Share_broad & & $0.329 \pm 0.198$ \\
N_Private & $2.352 \pm 1.937$ & $2.080 \pm 1.921$ \\
Women & 49.927 & 66.480 \\
Observations & 13,352 & 12,606 \\
\hline
\end{tabular}

Percentages are reported for discrete variables, and means and standard deviations are reported for continuous variables. For model 3, the observations were weighted by the number of inhabitants, and for model 4 , the weights were the number of prescriptions classified as either broad- or narrow-spectrum antibiotics. Descriptive statistics for age groups, municipality indicators, municipality-specific linear trends and the 60-month dummies are available upon request. For model 3, descriptive statistics are not reported for the weighted share of $2 \%$ of the observations for which N_antibiotics $=0$ because the dependent variable was not defined for these observations. The online Appendix shows that nearly identical results were obtained when the dependent variable was transformed so that all observations could be used in the estimation. For model 4, the number of observations is for observations with a strictly positive weight, that is, for which at least one antibiotic classified as either broad- or narrow-spectrum was prescribed. There was no missing information for model 4

with Muni_centre. Lastly, we included dummies for year $\times$ month combinations.

Model 4 included the same explanatory variables as those in model 3, but its dependent variable was Share_broad ${ }_{\text {ryas }}$. For each municipality of residence $x$ year $\times$ age group $\times$ sex combination, this variable equals the number of prescriptions of broad-spectrum antibiotics divided by the total number of prescriptions classified as either broad- or narrow-spectrum antibiotics. Models 3 and 4 were both estimated with ordinary least squares (OLS). In model 3, the observations were weighted using yearly data for the number of inhabitants in each municipality $x$ age group $\times$ sex combination, whereas the number of prescriptions classified as either broad- or narrow-spectrum antibiotics for each observation was used as weights in model 4 . Table 3 presents descriptive statistics for the dependent variables and some explanatory variables in models 3 and 4 . The value for the weighted share of women in model 4 means that $66 \%$ of prescriptions classified as either broad- or narrow-spectrum antibiotics were for women.

\section{Results}

Table 4 presents the main results for the study. For model 1 , the odds of prescribing an antibiotic were 1.06 higher for private health centres than for public centres, holding all other factors constant. This result can be interpreted in absolute terms using the fact that public physicians prescribed antibiotics in about $4.10 \%$ of cases, making the odds equal to 0.0428 . Then, for private health centres, the odds increased by $6 \%$ to 0.0454 , which means that the probability that a prescription was for an antibiotic was approximately $4.34 \%$. This is 0.24 percentage points higher than the probability for public health centres. In relative terms, 4.34 is $6 \%$ higher than 4.10 , meaning that the probability that a prescription was for an antibiotic was $6 \%$ higher for private health centres than for public centres, holding all other factors constant. Because the proportion of antibiotic prescriptions was very low, this increase in relative risk was approximately equal to the odds ratio minus one.

We also found significant effects of demographic variables on the probability that a prescription was for an antibiotic. According to the point estimates from the logistic regression of model 1 , this probability was higher for women than for men and decreased with age up to the 66-85 years age group. The estimate for Prescriptions_per_patient showed that the probability of a prescription being for an antibiotic was not significantly related to the average number of prescriptions per patient listed at the health centre.

The results for model 2 show that the odds of prescribing broad-spectrum antibiotics (versus narrow-spectrum antibiotics) were 1.14 higher for private health centres than for public centres. Public physicians prescribed broad-spectrum antibiotics in about $32.35 \%$ of the cases, making the odds approximately equal to 0.4782 . Hence, the model predicted the odds for private health centres to be about 0.5451 if they had prescribed to patients with the same demographics as the patients of county-employed physicians. This means that the probability of a broad-spectrum antibiotic being prescribed was approximately $35.28 \%$, which was 3 percentage points higher than the probability for public health centres. In relative terms, physicians in private centres were $9 \%$ more likely to choose a broad-spectrum antibiotic when prescribing any antibiotic than county-employed physicians, holding all other factors constant. The results for model 2 also showed that the probability of prescribing broad-spectrum antibiotics was lower for women and increased with age up to the 46-65 years age group.

In the online Appendix, we show that the results for models 1 and 2 are robust to using probit instead of logit estimation, to controlling for age by using the continuous variables age and age $^{2}$ instead of indicators for age groups, and to excluding municipality-specific linear trends.

Because the dependent variable in model 3 was in natural logarithms and the model was estimated with OLS, the coefficient estimates show the approximate ${ }^{1}$ percentage impact

\footnotetext{
1 The estimated percentage effect of a variable can be calculated using the formula $100 *\left[e^{B_{i}}-1\right]$, where $B_{i}$ is the coefficient estimate for the variable. For example, the estimated effect of a unit increase of $N \_$Private on $N \_$antibiotics is $100 *\left[e^{0.037}-1\right] \approx 3.8$.
} 
Table 4 Results of estimation, odds ratios for models 1 and 2, and coefficient estimates for models 3 and 4

\begin{tabular}{|c|c|c|c|c|}
\hline Model & 1 & 2 & 3 & 4 \\
\hline Private & $1.060 * * *(0.008)$ & $1.140 * * *(0.019)$ & & \\
\hline N_Private & & & $0.037 *(0.021)$ & $0.013(0.010)$ \\
\hline Women & $1.297 * * *(0.006)$ & $0.337 * * *(0.004)$ & $0.573 * * *(0.006)$ & $-0.236 * * *(0.003)$ \\
\hline Age group 3-6 & $1.232 * * *(0.023)$ & $0.817 * * *(0.035)$ & $-0.101 * * *(0.021)$ & $-0.031 * * *(0.009)$ \\
\hline Age group 7-12 & $0.917 *(0.018)$ & $0.762 * * *(0.035)$ & $-0.603 * * *(0.020)$ & $-0.040 * * *(0.009)$ \\
\hline Age group 13-18 & $0.825 * * *(0.015)$ & $1.193 * * *(0.051)$ & $-0.283 * * *(0.020)$ & $0.040 * * *(0.009)$ \\
\hline Age group 19-25 & $0.516 * * *(0.008)$ & $1.572 * * *(0.059)$ & $-0.430 * * *(0.018)$ & $0.091 * * *(0.008)$ \\
\hline Age group 26-45 & $0.236 * * *(0.004)$ & $1.913 * * *(0.065)$ & $-0.425 * * *(0.017)$ & $0.130 * * *(0.007)$ \\
\hline Age group 46-65 & $0.108 * * *(0.002)$ & $2.845^{* * *}(0.095)$ & $-0.223 * * *(0.017)$ & $0.216^{* * *}(0.007)$ \\
\hline Age group 66-85 & $0.089 * * *(0.001)$ & $2.260 * * *(0.074)$ & $0.338 * * *(0.017)$ & $0.161 * * *(0.007)$ \\
\hline Age group $\geq 86$ & $0.095 * * *(0.002)$ & $1.955 * * *(0.075)$ & $0.856 * * *(0.025)$ & $0.131 * * *(0.008)$ \\
\hline Prescriptions_per_patient & $0.997(0.004)$ & & & \\
\hline Year $\times$ Month FE & Yes & Yes & Yes & Yes \\
\hline Muni_centre FE & Yes & Yes & & \\
\hline Muni_centre linear trends & Yes & Yes & & \\
\hline Muni_patient FE & & & Yes & Yes \\
\hline Muni_patient linear trends & & & Yes & Yes \\
\hline Observations & $4,596,194$ & 152,055 & 13,352 & 12,606 \\
\hline Log likelihood & $-790,026$ & $-89,700$ & -3680 & 6550 \\
\hline$R^{2}$ & & & 0.699 & 0.473 \\
\hline
\end{tabular}

The dependent variables are as follows: model 1, an indicator for the prescribed drug being an antibiotic; model 2, an indicator for the prescribed antibiotic being broad-spectrum; model 3, the natural logarithm of the number of prescribed antibiotics per resident; model 4, the proportion of antibiotic prescriptions that are broad-spectrum. Standard errors derived from asymptotic theory under the assumption of independence between observations are shown in parentheses. Estimation results for year $\times$ month dummies, fixed effects and separate linear trends for the municipality where the health centre was located (Muni_centre), and fixed effects and the separate linear trend for the municipality of residence (Muni_ patient) are omitted to save space and are available upon request. $F E$ fixed effects, ${ }^{*} p<0.1, * * p<0.05, * * * p<0.01$

of the explanatory variables on the number of antibiotic prescriptions per capita. Hence, the estimate for N_Private indicates that one additional private health centre increased the number of antibiotic prescriptions in the municipality by nearly $4 \%$. It should however be noted that the effect of N_Private is estimated imprecisely because of the small variation in this variable and the estimate is only significantly different from zero at the $10 \%$ significance level. The results for model 3 also show that women and the elderly received more antibiotic prescriptions than men and younger individuals.

The point estimate for N_Private for model 4 is consistent with the presence of a higher number of private health centres leading to a larger proportion of broad-spectrum antibiotic prescriptions. However, the estimate is not statistically significant, which prevents us from concluding that this is indeed the case. In the online Appendix, we show that the estimate is significant at the $10 \%$ level if the natural logarithm of Share_broad ryas $_{\text {is }}$ is used as the dependent variable instead of Share_broad ${ }_{\text {ryas }}$. The result for model 4 confirms the result for model 2 that women and children were less likely to be prescribed a broad-spectrum antibiotic than men and older age groups.

\section{Discussion and Conclusions}

Growing rates of AR, caused by increasing antibiotic use, pose a threat to current and future generations due to antibiotic drugs becoming less effective in treating infectious diseases. Therefore, it is crucial to discover the factors affecting antibiotic use. Our results are consistent with the hypothesis that the incentives for private health centres to please patients may result in more prescription of antibiotics, and, in particular, broad-spectrum antibiotics.

The results of our first model show that physicians working at private health centres were $6 \%$ more likely to prescribe antibiotics than non-antibiotic drugs compared with county-employed physicians working in non-profit health centres. This result alone does not prove that private physicians are more likely to prescribe antibiotics than county-employed physicians for similar patients because unobserved characteristics can differ systematically between patients seeking care at private health centres and those seeking care at public centres. For example, it cannot be ruled out that patients with infectious diseases are more likely, for some reason, to visit private health centres. 
However, the results of model 3 show that the number of prescriptions for antibiotics increased with the number of private health centres in the municipality. This indicates that the result for model 1 is not entirely caused by patients needing antibiotic prescriptions to a greater extent choosing to visit private health centres. Instead, the results of models 1 and 3 are both consistent with physicians working at private health centres being more likely to prescribe antibiotics, all else being equal, so that an increase in the number of private health centres leads to more antibiotic prescriptions. However, other interpretations of the effects of a new private health centre are also possible. For example, a new private health centre increases competition for patients, which can affect the prescription behaviour of both public and private health centres. It can also increase access to primary care and therefore reduce the possibility that some patients refrain from seeking care.

The results from the second model show that private physicians, in addition to being more likely to prescribe antibiotics, were $9 \%$ more likely than county-employed physicians to choose broad-spectrum antibiotics. Even though a systematic variation in diagnoses between different health centres may also affect this result, we believe that the second model is much less vulnerable to these potential differences since it considers infectious diseases only. Thus, the result from the second model strengthens the support for our hypothesis that antibiotic prescription at private centres is affected by their stronger incentives to please patients.

The results also show significant difference in antibiotic prescriptions across demographic groups. Women are prescribed more antibiotics than men and this might be partly explained by women having a higher frequency of urinary tract infections, a common reason for antibiotic use [26]. In addition, according to model 3 , elderly patients are prescribed more antibiotics but, according to model 1 , the likelihood that a prescription is for an antibiotic is lower for elderly patients compared with younger patients. Together, these results suggest that elderly patients are prescribed more antibiotics per person, but are prescribed even more other drugs, making the proportion of antibiotic prescriptions lower for the elderly than for younger individuals.

An important limitation of this study is the lack of diagnostic information. This prevents us from drawing conclusions about the appropriateness of the antibiotic prescriptions made by county and privately employed physicians. In addition, the results of model 3 and 4 do not allow us to exclude the possibility that at least part of the differences across physician groups observed in models 1 and 2 are caused by the selection of patients. For this reason, future research should preferably be based on individual-level data on visits that includes diagnostic information, and the diagnoses should preferably be set by another physician than the prescribing physician to reduce the risk that the diagnoses set are adjusted to better motivate the prescriptions. Another limitation is that we do not have information about the prescribers' age, sex, or type of employment contract (e.g. permanent or temporary), therefore we cannot study if these factors dampen or increase the differences in prescription behaviour between private and public physicians.

The high use of antibiotics, especially broad-spectrum antibiotics, imposes a cost for society in terms of growing rates of AR. Privatisation can improve efficiency in healthcare provision. However, our results suggest that it may be especially important to monitor antibiotic prescription at private health centres, and to give these centres economic incentives to adhere to guidelines for antibiotic prescription.

Acknowledgements The authors are grateful to the County Council in Västerbotten for supplying the data used in this article, and to Øystein Myrland, Andrea Mannberg and Ilya Zykov for their helpful comments and suggestions.

\section{Declarations}

Funding Granlund acknowledges support from the Jan Wallander and Tom Hedelius Foundation and the Tore Browaldhs Foundation (Grant number P2016-0113:1). The publication charges for this article have been funded by a grant from the publication fund of UiT The Arctic University of Norway

\section{Conflict of interest None}

Ethics approval The regional ethical review board of Umeå declared that they found no ethical problem with this research project.

Consent to participate Not applicable.

Consent for publication Not applicable.

Data availability statement Subject to the appropriate ethics clearance, the dataset generated for the study is available from the authors on reasonable request.

Code availability The code is available from the authors on reasonable request.

Author contributions Both authors contributed equally to analysing the data and writing the manuscript.

Open Access This article is licensed under a Creative Commons Attribution-NonCommercial 4.0 International License, which permits any non-commercial use, sharing, adaptation, distribution and reproduction in any medium or format, as long as you give appropriate credit to the original author(s) and the source, provide a link to the Creative Commons licence, and indicate if changes were made. The images or other third party material in this article are included in the article's Creative Commons licence, unless indicated otherwise in a credit line to the material. If material is not included in the article's Creative Commons licence and your intended use is not permitted by statutory regulation or exceeds the permitted use, you will need to obtain permission directly from the copyright holder. To view a copy of this licence, visit http://creativecommons.org/licenses/by-nc/4.0/. 


\section{References}

1. Abadi ATB, Rizvanov AA, Haertlé T, Blatt NL. World Health Organization Report: current crisis of antibiotic resistance. BioNanoScience. 2019;9(4):778-88. https://doi.org/10.1007/s1266 8-019-00658-4.

2. Fleming-Dutra KE, Hersh AL, Shapiro DJ, Bartoces M, Enns EA, File TM, et al. Prevalence of inappropriate antibiotic prescriptions among US ambulatory care visits, 2010-2011. JAMA. 2016;315(17):1864-73. https://doi.org/10.1001/jama.2016.4151.

3. Avorn J, Solomon DH. Cultural and economic factors that (mis) shape antibiotic use: the nonpharmacologic basis of therapeutics. Ann Intern Med. 2000;133(2):128-35. https://doi. org/10.7326/0003-4819-133-2-200007180-00012.

4. Ashworth M, White P, Jongsma H, Schofield P, Armstrong D. Antibiotic prescribing and patient satisfaction in primary care in England: cross-sectional analysis of national patient survey data and prescribing data. Br J Gen Pract. 2016;66(642):e40-6. https ://doi.org/10.3399/bjgp15X688105.

5. Butler CC, Rollnick S, Pill R, Maggs-Rapport F, Stott N. Understanding the culture of prescribing: qualitative study of general practitioners' and patients' perceptions of antibiotics for sore throats. BMJ. 1998;317(7159):637-42. https://doi.org/10.1136/ bmj.317.7159.637.

6. Hamm RM, Hicks RJ, Bemben D. Antibiotics and respiratory infections: are patients more satisfied when expectations are met? J Fam Pract. 1996;43(1):56-62.

7. Zgierska A, Rabago D, Miller MM. Impact of patient satisfaction ratings on physicians and clinical care. Patient Prefer Adherence. 2014;8:437. https://doi.org/10.2147/PPA.S59077.

8. Gosden T, Forland F, Kristiansen I, Sutton M, Leese B, Giuffrida A, et al. Capitation, salary, fee-for-service and mixed systems of payment: effects on the behaviour of primary care physicians. Cochrane Syst Rev. 2000. https://doi.org/10.1002/14651858.

9. Hutchinson J, Foley R. Method of physician remuneration and rates of antibiotic prescription. Can Med Assoc J. 1999;160(7):1013-7.

10. Fogelberg S. Effects of competition between healthcare providers on prescription of antibiotics. IFN Working Paper 949: Research Institute of Industrial Economics; 2013. https://www.ifn.se/wfile s/wp/wp949.pdf. Accessed 18 Sept 2018.

11. Ellegård LM, Dietrichson J, Anell A. Can pay-for-performance to primary care providers stimulate appropriate use of antibiotics? Health Econ. 2018;27(1):e39-54. https://doi.org/10.1002/ hec. 3535

12. Silverman EM, Skinner JS, Fisher ES. The association between for-profit hospital ownership and increased Medicare spending. N Engl J Med. 1999;341(6):420-6. https://doi.org/10.1056/NEJM1 99908053410606.

13. Devereaux P, Schünemann HJ, Ravindran N, Bhandari M, Garg AX, Choi PT-L, et al. Comparison of mortality between private for-profit and private not-for-profit hemodialysis centers: a systematic review and meta-analysis. JAMA. 2002;288(19):2449_ 57. https://doi.org/10.1001/jama.288.19.2449.

14. Kessler DP, McClellan MB. The effects of hospital ownership on medical productivity. RAND J Econ. 2002;33(3):488-506.

15. Granlund D. Are private physicians more likely to veto generic substitution of prescribed pharmaceuticals? Soc Sci Med. 2009;69(11):1643-50. https://doi.org/10.1016/j.socsc imed.2009.09.016.

16. Ellegård LM. Effects of pay-for-performance on prescription of hypertension drugs among public and private primary care providers in Sweden. Int J Health Econ Manag. 2020;20:215-28. https ://doi.org/10.1007/s10754-020-09278-y.

17. Kaier K, Moog S. Economic consequences of the demography of MRSA patients and the impact of broad-spectrum antimicrobials. Appl Health Econ Health Policy. 2012;10(4):227-34. https://doi. org/10.2165/11631350-000000000-00000.

18. Mossialos E, Wenzl M, Osborn R, Sarnak D. 2015 International profiles of health care systems. The Commonwealth Fund; 2016. https://www.commonwealthfund.org/sites/default/files/docum ents/_media_files_publications_fund_report_2016_jan_1857_ mossialos_intl_profiles_2015_v7.pdf. Accessed 18 Sept 2018.

19. Anell A, Glenngard AH, Merkur SM. Sweden: Health system review. Health Syst Trans. 2012;14(5):1-159.

20. Anell A. Choice and privatisation in Swedish primary care. Health Econ Policy Law. 2011;6(4):549-69. https://doi.org/10.1017/ S1744133110000216.

21. Nordqvist L, Jönsson S, Bern A, Larsson K, Lind H. Etablering och konkurrens bland vårdcentraler-om kvalitetsdriven konkurrens och ekonomiska villkor. Konkurrensverkets rapportserie. Stockholm. 2014. https://www.konkurrensverket.se/globalasse ts/publikationer/rapporter/rapport_2014-2.pdf. Accessed 18 Sept 2018.

22. Anell A, Nylinder P, Glenngård A. Vårdval i primärvården: jämförelse av uppdrag, ersättningsprinciper och kostnadsansvar: Stockholm: Sveriges Kommuner och Landsting; 2012. https:// lup.lub.lu.se/record/3357756. Accessed 18 Sept 2018.

23. Lundvall K, Öhlin J, Stefansdotter A. Inträdeshinder för privata vårdcentraler: Erfarenheter från valfrihetsreformen inom primärvård. Uppdragsforskningsrapport, Konkurrensverket, Stockholm. 2011. https://www.konkurrensverket.se/globalassets/ publikationer/uppdragsforskning/forsk_rap_2011-4.pdf. Accessed 18 Sept 2018.

24. Uhlin G. Landstingsstyrelsens styrning, uppföljning och kontroll av primärvården inom hälsoval Västerbotten. Landstingsrevisionen Västerbottens Läns Landsting, Earnst \& Young; 2011.

25. Sundvall P-D, Stuart B, Davis M, Roderick P, Moore M. Antibiotic use in the care home setting: a retrospective cohort study analysing routine data. BMC Geriatr. 2015;15(1):71. https://doi. org/10.1186/s12877-015-0073-5.

26. Smith DRM, Dolk FCK, Smieszek T, Robotham JV, Pouwels $\mathrm{KB}$. Understanding the gender gap in antibiotic prescribing: a cross-sectional analysis of English primary care. BMJ Open. 2018;8(2):e020203. https://doi.org/10.1136/bmjopen-2017-020203. 